The definitive, peer-reviewed and edited version of this article is published as

Banister, David; Givoni, Moshe, Built Environment, Volume 39, Number 3, October 2013, pp. 324-338(15) Publisher: Alexandrine Press 


\title{
High Speed Rail in the EU27: Trends, Time, Accessibility and Principles
}

\author{
David Banister $^{1}$ and Moshe Givoni ${ }^{1,2}$ \\ ${ }^{1}$ Transport Studies Unit, School of Geography and the Environment, University of Oxford, \\ Oxford, OX1 3QY, UK. Email: david.banister@ouce.ox.ac.uk \\ ${ }^{2}$ Department of Geography and Human Environment, Tel-Aviv University, POB 39040, \\ Ramat Aviv, Tel Aviv 69978, Israel. Email: givonim@post.tau.ac.il
}

"Modern economies cannot generate wealth and employment without highly efficient transport networks” Jacques Barrot, Vice President of the European Commission with responsibility for transport (EC, 2005, p3).

\section{Introduction - Rail and High-Speed Rail in Europe}

Central to the EU's transport strategy as set out in the 2011 White Paper (EC, 2011) are the plans to complete the TEN-T network of the key road and rail links within the EU27. By 2020 , the TEN-T will include $89,000 \mathrm{~km}$ of roads and $94,000 \mathrm{~km}$ of railways, and about $20,000 \mathrm{~km}$ of these will be high speed rail (HSR) lines suitable for speeds of at least $200 \mathrm{~km} / \mathrm{h}$. There are also plans for investment in the inland waterways network, seaports and airports. The 'backbone' for the TEN-T is the completion of 30 priority axes, 18 of which are railway projects and a further 3 are multimodal projects, including a rail element. The total cost for these 30 TEN-T priority axes (2005) was estimated to be €252 billion, including the $€ 112$ billion already spent to complete the original 14 priority projects (the Essen Projects). It is estimated that this investment amounts to $0.16 \%$ of EU GDP and that economic growth will be increased by $0.23 \%$ of GDP (EC, 2005).

There are five main sources of funding, including the direct contributions from the EU, together with additional inputs from the cohesion funds and the structural funds (European Reconstruction and Development Fund) for eligible locations in the peripheral countries of the EU or in the recent member states (mainly from eastern Europe). These sources account for about 15 per cent of the total costs, and a similar amount would come from loans issued through the European Investment Bank (EIB). The balance would be funded by the individual Member States and other sources, including the private sector (Table 1).

In the past nearly half the investment has come from the EU, but this has now changed with only 30 per cent being available from the EU. This reflects both the increased ambition in terms of the network extent and the limitations on funding now and into the future. Yet the railways are still seen as being central to the EU Single Market and it provides the most visible symbol of that integration. The $2012 \mathrm{EU}$ Summit (October) reinforced this view with the proposal to develop a new $€ 50$ billion fund for "Connecting Europe Facility" (CEF) that would promote the new trans European networks, including transport, energy and telecommunications. But progress is likely to be slow as other demands compete for the more limited funds that are available. There is considerable uncertainty over the future funding for rail in the EU. 
Over the last 15 years, demand for rail transport in the EU27 ${ }^{1}$ has increased, but the steady growth in the EU15 countries (+30 per cent 1995-2010) is matched by a substantial decline in the EU12 countries (-40 per cent 1995-2010) (DG TREN, 2012). Since the 1970s there has been a steady growth in rail travel in the EU27, reflecting the general growth in mobility by all forms of transport.

Table 1: The 30 EU Priority Projects Funding

\begin{tabular}{|l|c|c|c|}
\hline TEN-T Priority Projects & $\begin{array}{c}1993 / 96-1999 \\
\text { EU15 }\end{array}$ & $\begin{array}{c}2000-2006 \\
\text { EU27 }\end{array}$ & $\begin{array}{c}2007-2012 \\
\text { EU27 }\end{array}$ \\
\hline Cost (€ billion) & & & \\
TEN-T 30 & 32.65 & 93.70 & 154.0 \\
$\quad$ New Member States (EU12) & & & 16.0 \\
Old Member States (EU15) & & & 138.0 \\
\hline Community Contribution (€ billion) & 1.35 & 2.80 & 5.4 \\
$\quad$ Programme TEN-T & 3.83 & 7.00 & 12.3 \\
Cohesion Fund & 1.46 & 4.81 & 4.7 \\
ERDF & 9.78 & 16.10 & 25.0 \\
EIB Loans and Guarantees & & & \\
Total Community Contribution (€ billion) & $6.64(20.3 \%)$ & $14.61(15.6 \%)$ & $22.4(14.5 \%)$ \\
$\quad$ Grants & $16.42(50.3 \%)$ & $30.71(32.8 \%)$ & $47.4(30.8 \%)$ \\
$\quad$ Grants and Loans & $16.23(49.7 \%)$ & $62.99(67.2 \%)$ & $106.6(69.2 \%)$ \\
\hline Other Resources - National
\end{tabular}

Source: http://ec.europa.eu/transport/themes/infrastructure/ten-t-funding-and-financing/doc/funding figs.pdf Accessed 21st October 2012.

One explanation for the very variable patterns in rail travel between the different EU countries has been the investment in HSR, as this is where most activity has taken place, often at the expense of other rail services. The concentration of available national funding, together with complementary EU support, has resulted in high quality fast and frequent services between some of the main cities in France, but a corresponding decline in demand for regional and local rail services (Crozet, 2011). From Table 2, it can be seen that rail accounts for less than 7 per cent of all travel in the EU27, but that there has been a steady growth over the last 15 years. Overall, the main growth in travel has been by air and car, and these two modes account for most of the 22 per cent increase in distance travelled.

Table 2: EU27 Performance by Mode

\begin{tabular}{|l|c|c|c|c|c|c|}
\hline Thousand M pkm & 1995 & 2000 & 2005 & 2010 & 2011 & \% increase \\
\hline Car & 3930 & 4372 & 4630 & 4832 & 4822 & +23 \\
Bus and Coach & 499 & 517 & 523 & 509 & 512 & +3 \\
Rail & 351 & 371 & 377 & 404 & 407 & +16 \\
Air & 346 & 457 & 527 & 522 & 575 & +66 \\
Other & 237 & 229 & 247 & 251 & 253 & +7 \\
\hline Total & 5363 & 5946 & 6304 & 6518 & 6569 & +22 \\
\hline
\end{tabular}

Notes: Other includes sea, two wheelers, tram and metro; Air only includes travel within the EU27 Source: DG TREN (2013)

\footnotetext{
${ }^{1}$ In this paper there is frequent mention of EU27, EU15 and EU12. The EU27 refers to all the current member states of the European Union (EU15 + EU12). The EU15 refer to those member states that were part of the EU in 1995 (France, Germany, UK, Sweden, Finland, Denmark, the Netherlands, Belgium, Luxembourg, Ireland, Italy, Spain Portugal, Greece, and Austria) and the EU12 refers to those states that have joined since 2004 (Poland, Czech Republic, Slovak Republic, Hungary, Slovenia, Cyprus, Malta, Estonia, Latvia, Lithuania, Bulgaria and Romania). Croatia joined in 2013, but it is not included in any of the published data.
} 
However, it is within the rail sector that most change has taken place over the 16 year period, as HSR now accounts for over 27 per cent of all rail travel in the EU27 (Table 3).

Table 3: HSR in EU27

\begin{tabular}{|l|c|c|c|c|c|}
\hline Thousand M pkm & 1995 & 2000 & 2005 & 2010 & 2011 \\
\hline France & 21.43 & 34.75 & 43.13 & 51.89 & 52.04 \\
Germany & 8.70 & 13.93 & 20.85 & 23.90 & 23.31 \\
Spain & 1.29 & 1.94 & 2.32 & 11.72 & 11.23 \\
Italy & 1.10 & 5.09 & 8.55 & 11.61 & 12.28 \\
Sweden & 0.42 & 2.05 & 2.33 & 2.94 & 2.83 \\
Belgium & - & 0.87 & 0.98 & 1.06 & 0.91 \\
UK & - & - & 0.45 & 1.01 & 5.98 \\
Others & - & 0.17 & 1.50 & 1.75 & 1.77 \\
\hline Total & 32.94 & 58.80 & 80.11 & 105.87 & 110.35 \\
\% of all rail & 9.4 & 15.9 & 21.2 & 26.2 & 27.1 \\
\hline
\end{tabular}

Note: Other includes Czech Republic, the Netherlands, Portugal, Finland and Slovenia. HSR includes trains able to travel at more than $200 \mathrm{~km} / \mathrm{h}$

Source: DG TREN (2013)

The figures for the individual countries are even higher, with HSR investment being concentrated in four countries. In France, it accounts for 58 per cent of all rail travel, and in Spain for 49 per cent. The figures for Germany and Italy are 27 per cent and 28 per cent respectively. This reflects the competitive position of HSR in each of these countries, the high levels of investment, and the advantages in terms of the network economies achieved. This means that HSR develops from being a set of individual routes to allow travel to take place across a network of connected routes, both nationally and internationally. HSR has driven the rail renaissance in the four countries in the EU27 that have followed this network strategy, but this may have been at the expense of travel on conventional rail. In each of these countries, the travel on conventional rail (1995-2011) has either been stable (France +8 per cent; Germany -1 per cent) or it has declined (Spain -24 per cent; Italy -32 per cent), so the growth in rail travel has been concentrated on the HSR routes.

In those $7 \mathrm{EU}$ countries (in the EU15) that have not invested in the HSR option to any great extent (Portugal, Denmark, Ireland, Greece, Austria, Finland, and Luxembourg), the overall growth in rail travel has been substantially lower than in those countries that have invested heavily in HSR (+8 per cent - Table 4). It should also be noted that these are all small countries, and individually there has been substantial change, both through increases and decreases in rail travel.

The most remarkable increases have come in the four EU countries (Belgium, the Netherlands, the UK and Sweden) where there has been limited investment in HSR, as the growth in rail travel (1995-2011) is higher than those that have invested in extensive HSR networks (Table 4), with an overall increase of 56 per cent. Part of the explanation of this counter intuitive observation is the huge increase in rail travel in the UK (+87 per cent, 1995-2011), but there have also been substantial increases in Sweden and Belgium. The four countries that have invested most heavily in HSR are the larger EU countries, which account for about 66 per cent of all rail travel, but this proportion has not changed, even though the rail market grew by over 30 per cent overall during this 16 year period (Table 4).

The large increases in France and Spain are balanced by lower growth in Germany and a decline in Italy. One conclusion here is that the investment in HSR has not resulted in greater growth in the rail market in these four countries, than that which has taken place in 
those other countries that have made limited investment in HSR. The main impact has been in the redistribution of travel within the rail market from slower to faster rail travel. The measure used (pkm) also means that the overall distance travelled by all forms of rail travel in the EU15 have increased substantially, and that the contribution of HSR to this figure cannot be viewed in isolation. As there is no available data on the numbers of journeys made by HSR and conventional rail, it is unclear whether the average trip lengths have increased. Overall, the figures presented for the different EU countries with respect to rail use and investments in HSR do not point to a clear correlation. This needs to be investigated in more detail, but it is clear that heavy investments in HSR do not guarantee growth in rail use and certainly not mode shift to rail from other modes.

Table 4: Growth in Rail Travel in the EU15

\begin{tabular}{|c|c|c|c|c|c|c|c|}
\hline \multicolumn{4}{|c|}{ Countries not investing in HSR } & \multicolumn{4}{|c|}{ Countries with heavy investment in HSR } \\
\hline $\begin{array}{l}\text { Thousand M } \\
\text { pkm }\end{array}$ & 1995 & 2011 & \% change & $\begin{array}{l}\text { Thousand } \\
\text { M pkm }\end{array}$ & 1995 & 2011 & \% change \\
\hline Portugal & 4.8 & 4.1 & -15 & France & 55.6 & 89.0 & +60 \\
\hline Denmark & 4.9 & 6.6 & +35 & Germany & 71.0 & 85.0 & +20 \\
\hline Ireland & 1.3 & 1.6 & +31 & Spain & 16.6 & 22.8 & +37 \\
\hline Greece & 1.6 & 1.0 & -38 & Italy & 46.7 & 43.3 & -7 \\
\hline Austria & 10.1 & 10.9 & +8 & & & & \\
\hline Finland & 3.2 & 3.9 & +22 & & & & \\
\hline Luxembourg & 0.3 & 0.3 & - & & & & \\
\hline Total & 26.2 & 28.4 & +8 & & 189.9 & 240.1 & +26 \\
\hline
\end{tabular}

\begin{tabular}{|l|c|c|c|}
\hline \multicolumn{4}{|c|}{ Countries with limited investment in HSR } \\
\hline $\begin{array}{l}\text { Thousand M } \\
\text { pkm }\end{array}$ & 1995 & 2010 & $\%$ change \\
\hline Belgium & 6.8 & 10.4 & +53 \\
Netherlands & 16.4 & 15.7 & -4 \\
UK & 30.3 & 56.6 & +87 \\
Sweden & 6.8 & 11.4 & +68 \\
\hline Total & 60.3 & 94.1 & +56 \\
\hline
\end{tabular}

Source: DG TREN (2013).

Length of High Speed Rail Network 2012 (Kms)

\begin{tabular}{|l|c|l|c|}
\hline \multicolumn{2}{|l|}{$\begin{array}{l}\text { Countries with high levels of } \\
\text { investment in HSR }\end{array}$} & \multicolumn{2}{|l|}{$\begin{array}{l}\text { Countries with limited } \\
\text { investment in HSR }\end{array}$} \\
\hline Spain & 2144 & Belgium & 209 \\
France & 2036 & Netherlands & 120 \\
Germany & 1334 & UK & 113 \\
Italy & 923 & Sweden & \\
\hline Total & $6437 \mathrm{kms}$ & Total & $442 \mathrm{kms}$ \\
\hline
\end{tabular}

Note that all the 17 new HSR lines currently under construction are in Spain (10), France (4) and Germany (3) - three will be in operation in 2015, and a further 4 in 2016 and 2017.

HSR means that the numbers of stations on the network are fewer, and that less frequent stops (trains often not stopping at all the stations they pass through) are made as compared with conventional rail services. This has important implications for the spatial distribution of HSR use within countries, and thus rail use more generally, that needs to be recognised also where HSR appears to contribute to growth in rail use. Only the largest cities and the most densely populated areas within a country will be served, while within cities only certain areas will benefit from a relatively close and accessible HSR station. An exception 
is when the HSR can also run on the conventional rail network, like in France, but even there is still cover only relatively small part of the rail network. The location of the high speed train (HST) stations, close to employment centres in the service sector and/or city centres means that there is also unequal access to HSR services with respect to the socioeconomic profile of the population. Coupled with the usually higher fares for travelling on the HSR, the increasing use of HSR also implies unequal distribution of the benefits from HSR. These inequalities are both spatial and social. In the remainder of the paper we outline some of the main elements needed to realise the potential of HSR.

\section{Travel Time}

Within a resource constrained world it is important to make the most efficient use of energy and to move towards low carbon mobility. Rail is an efficient user of energy provided that there are sufficient densities in terms of passenger and freight demand, and this is now evident in the dominance that rail has established in certain transport corridors, for example in the UK between London and Manchester, in France between Paris and Lyon, and in Japan between Tokyo and Osaka. As noted above in Table 3, HST now accounts for over 27 per cent of all rail travel in the EU27, as there is a sufficient network density in several countries to provide a new, fast, convenient and fashionable mode of transport (Givoni and Banister, 2012a).

The transport paradigm views travel time as 'wasted time' that should be minimised, and this rationale has underpinned the arguments for HSR, as it reduces travel time through higher speeds (Banister, 2011). There are a series of issues raised with this perspective, particularly if resource use and carbon reduction are also central policy objectives, as promoted in the sustainable mobility paradigm (Banister, 2008).

Firstly, even though rail is an efficient means for moving people (and freight) around, it still uses more energy if it is travelling at high speed. The carbon content of the energy will be reduced if the power used is electricity, provided that it is generated from renewables or from nuclear sources (as in France) (Givoni et al., 2009). But there is also energy embedded in the infrastructure, the rolling stock, the operating systems and even the stations that would need to be included in an overall balance sheet of HSR's carbon and energy footprint (see Chester and Horvath, 2010).

Secondly, the label high speed is what might appeal in HSR, yet even this concept is open to debate, as definitions revolve around the maximum speed rather than the average speed. The number of stops on the HSR line and the proportion of the line that can be operated at the maximum speed both determine the end to end average speed. Additional stops will add at least 5 minutes to the travel time, and even the worlds most successful HST line in terms of passengers carried and density of traffic between Tokyo and Osaka has an average speed of less than $240 \mathrm{~km} / \mathrm{hr}$ (Givoni and Banister, 2012b). So the headline figures on the maximum speed only tells part of the story, and for the passenger it is the complete journey time that is important, not just the high speed part of that journey. The difference between the maximum design speed and the actual average speed is well illustrated in Figure 1 where it can be seen that the Méditerranée comes nearest to having both the maximum and the average speed close to one another. This is due mainly to the relatively low number of stations on that particular line. 
Figure 1: Maximum and average speeds on selected EU HSR lines

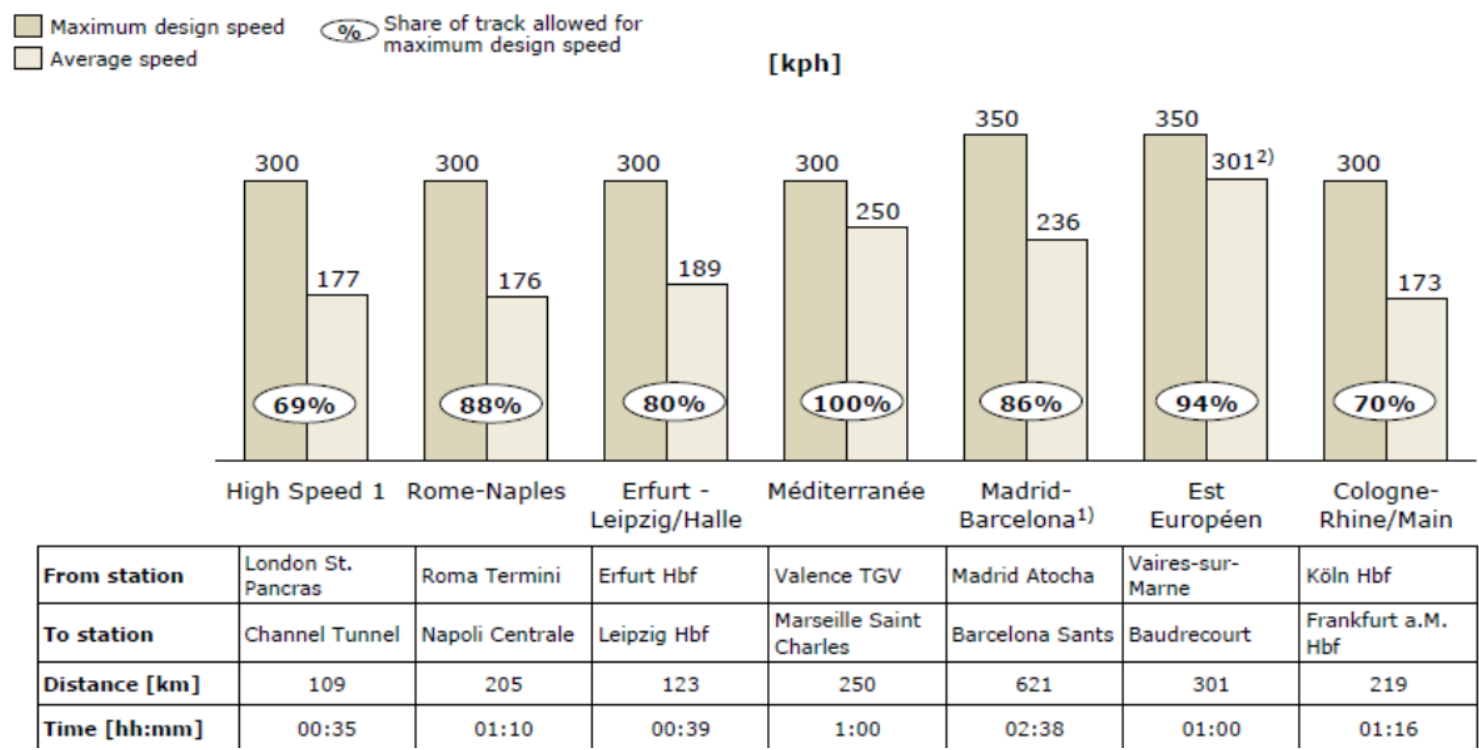

Notes: 1) Current speed is $300 \mathrm{~km} / \mathrm{hr}$

Source: BSL Management Consultants (2009) Comparison of High Speed Lines, Final Report for Lloyds Register, Hamburg, November, http://www.hs2.org.uk/assets/x/56773 - Last accessed 6th November 2012.

Thirdly, this means that it is the convenience, reliability, cost and comfort that determine the quality of the travel experience for the entire journey, not just the travel time. So HSR travel might not be attractive to many users, even though it has an attractive high speed (HS) image, as it is often difficult to get access to stations (see below). This means that time savings from the HSR section of the journey are 'lost' through the additional time taken to get to and from the HSR stations. In addition, travel on the HSR is often made through pre-booking specific trains, and so the important element of flexibility offered by slower more frequent services may be lost, and as HSR are more expensive, an element of affordability is also lost.

Finally, much of the time spent on the HST is quality time that can be used for a range of work, social and leisure activities. It is not wasted time, and with the wide availability of mobile services it provides a high quality work space with internet access and mobile phone connectivity. This suggests that travel time on HST should be considered as work (or leisure) time and valued accordingly, as it creates new patterns of time use. With increasingly flexible forms of working, considerable use has to be made of time when travelling. In this sense travel by HSR, where there is often sufficient time for concentrated and undisturbed activity, should be seen as productive time and not wasted time. Thus, some of the rationale for HS, certainly from an economic perspective (limiting 'waste' of time) is lost due to the superior travelling environment on board the HSR.

There are many benefits of HSR in terms of its image and role in redefining rail travel, yet the very notion of high speed reinforces the conventional views on travel time. New thinking is required that examines door to door travel time and the connectivity between different types of rail journeys (high and low speed), as well as between rail and other modes of transport. This thinking moves away from looking at parts of a journey by a series of independent modes of transport towards coordination within one mode of transport (rail) and integration across modes of transport. It is looking at the transport system as a whole and how the different parts (including HSR) link together efficiently and effectively. Travel time is one important element in that system, but it seems to dominate other 
important aspects of the quality of the overall service being provided for the entire journey. These other elements must be seen as important elements when planning HSR.

Travel time is not uniform in terms of its potential value to the traveller, and provided that other important factors are also included in the service being provided (e.g. comfort, designated work space, internet access etc), time can be effectively used whilst travelling. Travel is no longer only about speed, it is about how travel time is used. Perhaps it is now opportune that rail transport should be considered as part of a door to door service that provides travel that is faster than road, but at the same time provides high quality environments in which people can use their travel time more effectively. Slower speeds could make rail services more reliable, but still faster (than other modes), with a better overall experience in terms of comfort and use of time. Looking at speed in a wider context presents an opportunity to treat other important factors in HSR planning as part of the total service being provided to the user.

\section{Accessibility}

Improved accessibility is a prerequisite for any benefits from the development of HSR. This refers to the benefits of users and benefits to society, including non-users. It is related to the direct transport benefits from improved accessibility and to the potential for 'non-transport' benefits, including wider economic benefits and environmental benefits. Improved accessibility, including shorter travel time on the entire journey (door-to-door and not only station-to-station) is very much a factor of three interlinked components: the number of HSR stations, their location, and their integration with the rest of the existing and planned transport network. Following from the discussion on travel time, it is clear that accessibility as discussed here should be the focus for securing the benefits from HSR. For example, Brons et al., (2009) found that improved accessibility of the station is the third most important service attribute (out of ten) to improve, if the Dutch Railways (NS) want to raise the levels of passengers satisfaction (after travel time reliability and price-quality ratio). In Taiwan, Chou et al. (2011) found that the location of the HSR stations away from the city-centre, and (partly as a result) the access to them is perceived as being the least appreciated attributes of the HSR service. The perceived poor accessibility of the HSR service in Taiwan is seen to be the result of the disconnection between the HSR and conventional rail networks. To illustrate this issue we focus here on the existing and planned HSR in the UK, but there is a wider discussion in Ureña (2009) that focuses on similar issues with respect to smaller, intermediate cities.

\subsection{The number of stations}

A simple economic model for the optimal number of rail stations suggests that it is made up of a combination of the costs of providing the station (e.g. construction) and the costs of stopping a train in that station ('waste' of time for those passengers not using that station) on the one hand, and the costs of accessing the station on the other (Givoni and Rietveld, 2011). According to this model there is a case for providing an additional station when the reduction in the access cost is larger than the cost of providing the station and the travel time penalty to those rail passengers only passing through the station. The conclusion reached in subsequent empirical modelling work on the Amsterdam region is that increasing the number of stations would be welfare enhancing, and that analysis should integrate rail and local public transport services with a focus on the number of stations within the urban area (Givoni and Rietveld, 2013). 
The nature of HSR service means that every station is both expensive to provide (in terms of land acquisition and construction costs) and in terms of the time penalty for stopping a HSR service. The HSR network includes relatively few stops, compared with the slower, conventional rail, and even if this number is high not all HSTs will stop at each station. But there is no rationale for investing in HSR infrastructure capable of supporting high speed if the line includes too many stations. In the UK, on the High-Speed1 line connecting London and Channel Tunnel and designed for a speed of $230-300 \mathrm{~km} / \mathrm{hr}$, there are four stations on a $108 \mathrm{~km}$ line (one in London and then after 9, 37 and $90 \mathrm{~km}$ ). This number is too many and it translates into an intermittent service, as most trains do not stop at all the stations.

The nature of HSR, even when HS is kept to above an average speed of $200 \mathrm{~km} / \mathrm{hr}$ and not much more, means that when improving the accessibility of the HSR service, the focus should be on improving access to the stations rather than increasing the number of stations. It is therefore expected that only in large metropolitan cities, generally of a few million inhabitants, there will be a case for more than one station. In cities which are large in area but not in population (i.e. where the city is low density), there will be even less of a case for providing more than one station, although in such places, given the size of the city, one station means an especially long access journey ${ }^{2}$.

Another component of the above model is the volume of demand. In general, as demand increases there is a case for providing more stations. This also holds for HSR, but the level of demand required to justify the provision of a station (or an additional station) is very high. This limits the possibilities in many cities to provide more than one station.

In the case of the planned High-Speed2 line in the UK (connecting London to the North, initially only to Birmingham) it seems more reasonable to provide two stations in London (7.5 million population) than providing two stations in Birmingham (population just over 1 million). Current plans provide for two stations in each of the cities, most likely with no stations in between.

\subsection{Station location}

The location of the station within a city is also a key consideration. In general it is derived from the above model, and it is seen as a factor of the spatial 'concentration' of demand for HSR, and the potential development around the station (availability of land for development is key here), which can be seen as potential future demand. In addition, the alignment of the proposed HSR line also plays an important factor, since any deviation from the shortest path connecting the start and end of line stations is costly, both financially and in terms of time. Finally, the nature and spatial organisation of the local transport network should also play a central role in the decision on the station(s) location, in particular the location of the main interchange points on the local public transport network.

There are two general options in terms of station location within the city. One is the 'city centre' location and the other is location in the 'city outskirts'. The main advantages of the city centre location are that it is usually where much of the economic activity is concentrated, especially the service sector that generates commuting and business trips. It is usually the 'centre' point of the urban public transport network, and where the conventional rail stations are located; and it is also usually a high-density residential area.

In contrast, the characteristics of the city centre location also make it difficult and costly to construct a station. First, the availability of land to locate the station is difficult (the current

\footnotetext{
${ }^{2}$ This is a challenge in particular for cities in the US which bear this characteristic.
} 
Eurostar trains operating between London and Paris or Brussels are 394m long), and most likely it will require vacating some existing land uses. Furthermore, the land values are high. It is also likely to be more disruptive to the city and to its population during the construction phase when the station location is in the city centre. Finally, 'bringing' the line to the city centre, and/or taking it out of the city centre will be similarly expensive and complicated, often requiring tunnels. In cities where for historic reasons the centre (or parts of it) has become largely derelict and underdeveloped, the opportunity provided by HSR for locating the station in the city centre is less problematical, and it can provide the impetus for the regeneration of the city centre. This consideration was central in locating the terminal station on the Channel-Tunnel Rail Link (HS1) in St. Pancras, where the magnificent $19^{\text {th }}$ Century station has been taken over and the platforms lengthened to accommodate the HST. The Kings Cross Railway Lands (25 ha) that adjoins St Pancras and Kings Cross stations has now been redeveloped as a high quality housing (with affordable homes), business and commercial area, with centres for education and the arts.

The discussion over the outskirt location option is basically a mirror picture of the city centre location. The advantages relate mainly to availability of land for the station and for development around it, and the ability to bypass the dense urban area when planning and constructing the line. The main disadvantage is the relative remoteness of the station with respect to centre of population, economic activity and public transport network. In terms of accessibility, however, city outskirts location of the station will usually mean better accessibility by car (also due to the possibility to provide larger parking areas) and thus overall better access to HSR services from the surrounding area which is outside the city.

The low levels of demand for HSR in the city outskirts can be addressed by locating the station next to an airport in the city outskirts. HSR has, and does, play an important role in air transport, both as a complementary mode of transport to the aircraft and a competitor to the aircraft (Givoni and Banister, 2007). One of the EU targets stated in the White Paper is that "By 2050, connect all core network airports to the rail network, preferably highspeed..." (EC, 2011: 9), and this possibility has been taken up in several cities in the EU27, including Frankfurt, Paris and Amsterdam (see Section 3.3).

\subsection{Integration with the rest of the transport network}

The conventional rationale means that there is only one HSR station per city and wherever it is located (centrally or peripherally), it is the integration with the rest of the transport network that will determine the overall accessibility of the HSR service. As HSR is a long distance surface mode of transport, there are three levels of integration that should be considered. At the local level, it is largely at the city level, where integration with the local public transport network can take place so that good accessibility from a large part of the urban area is assured. By minimising the number of transfers required on the local public transport network, good access to the HSR is guaranteed, and given the nature of HSR travel, the inconvenience and time penalty associated with accessing the HSR station can be reduced. Thus the station should be 'on' as many as possible metro, tram, and bus lines. This will favour city centre location.

Figure 2 demonstrates how good integration between rail and the local public transport public can make a rail station attractive also when there are other, 'closer' stations in that area. In Figure 2 all stations (large dots) are conventional rail stations but Amsterdam Centraal station (marked 1) capture close to 60 per cent of passengers departing from the Amsterdam area. The small dots in Figure 2 show postcodes (at the 6-digit level) where at 
least one passenger was recorded as using Amsterdam Centraal station as "the usual departure station" in a survey of the Dutch railways (Givoni and Rietveld, 2011) .

At the regional level, the road and rail networks are central for good accessibility. If the use of public transport is to be encouraged, then locating the HSR station where the existing conventional rail stations are is paramount, as conventional rail is often the most important feeder of passengers for the HSR services. In Europe, this again will generally favour city centre location for the station. Improved accessibility for the HSR station through the regional rail network is however not always guaranteed, and it depends on the organisation of the conventional rail network. Figure 3 shows how a proposed HSR station at Birmingham will affect the accessibility of London (not on the map) by rail. For most of the stations in the Birmingham area, the planned HSR line would not improve accessibility. The decision to locate the HSR station in Birmingham near to (a few hundred metres apart) and not together under the same roof as the main conventional rail station (New Street station in central Birmingham is one of the largest in the country and a central point of the national railway network) only makes regional accessibility worse (this aspect is not accounted for in Figure 3).

Figure 2: The catchment area of Amsterdam Centraal station

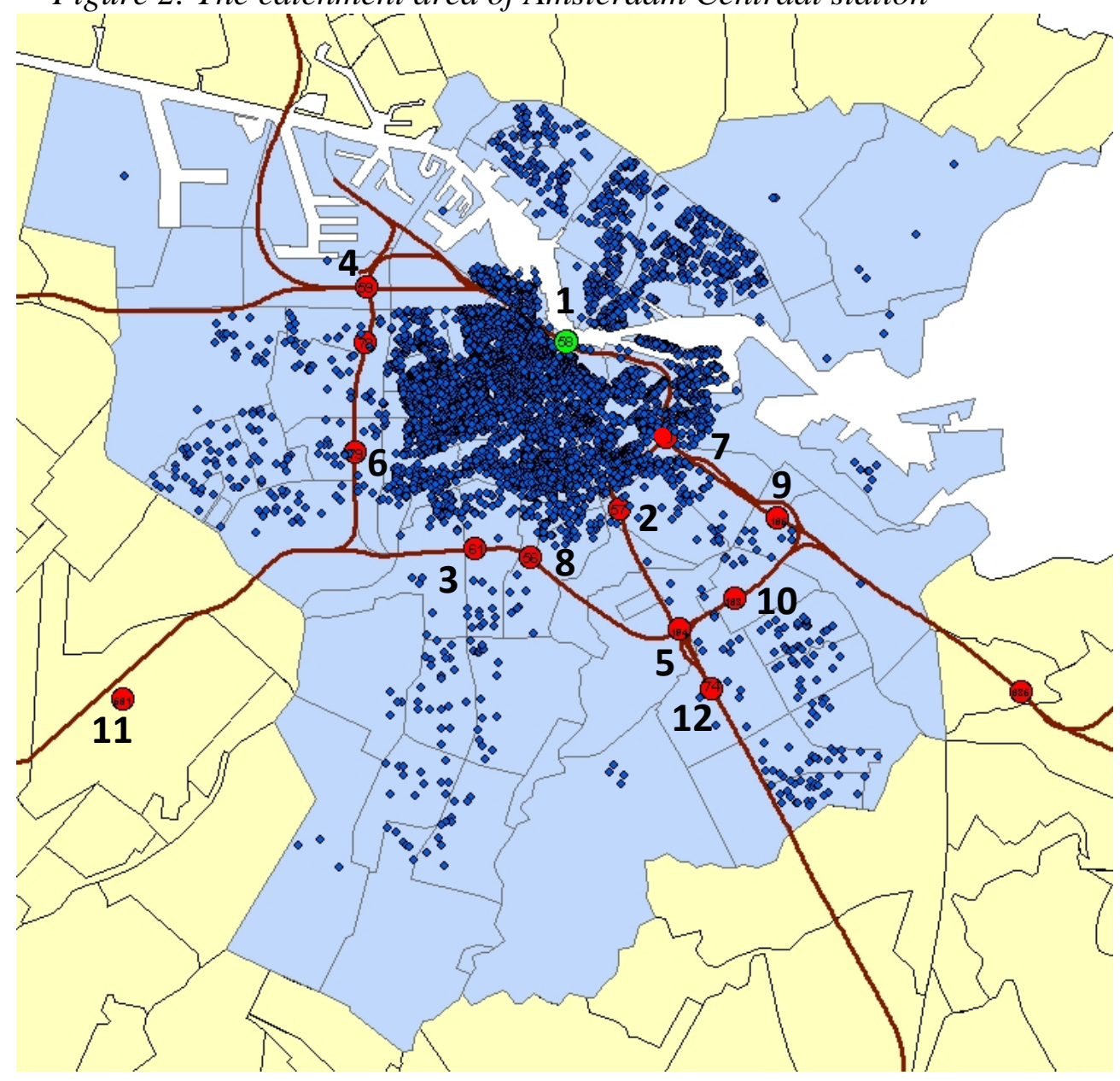

Index: 1 - Amsterdam Centraal; 2 - Amsterdam Amstel; 3 - Amsterdam Zuid; 4 - Amsterdam Sloterdijk; 5 Duivendrecht; 6 - Amsterdam Lelylaan; 7 - Amsterdam Muiderpoort; 8 - Amsterdam RAI; 9 - Diemen; 10 Diemen Zuid; 11 - Schiphol; 12 - Amsterdam Bijlmer.

Source: Givoni and Rietveld, 2011. 
The last level of integration is with the airports and air transport networks. Givoni and Banister (2006) showed for London Heathrow airport that about 20 per cent of the runway capacity used in the airport (probably the world's most congested airport) could be transferred to a future HSR network with almost no time penalties, and if the proposed EU HSR network were to be completed and the airport becomes a station 'on-the-line'. The growth in demand for rail travel (and HSR especially) at large international airports makes them, from a rail planning perspective, equal to large cities or even larger in terms of their capacity to generate passengers. In the Netherlands, Amsterdam Schiphol station (Amsterdam airport, station 11 in Figure 2) has gradually gained in importance over Amsterdam Centraal station on the Dutch rail network. The demand generated by the airport also allows this station to become an important transfer point between routes on the conventional rail network. In 2006, the airport station had direct rail services to 54 stations on the Dutch rail network, out of about 350 stations, and another 169 stations could be reached via one transfer. With up to 2 transfers, more than 95 per cent of the stations on the Dutch network could be reached. In terms of rail accessibility, this station was ranked fifth in the Netherlands in service quality, before Amsterdam Centraal station (Givoni and Rietveld, 2008 based on Debrezion, 2006). Later the rail network was reorganised and a bridge constructed to allow more direct services to the airport, especially from Utrecht (the centre of the Dutch rail network) and the south east parts of the country. This also allows Schiphol airport to be an important node on the European HSR network with direct services to Brussels (and from there to Paris and London, the latter still not in operation) and the German HSR network (ibid.).

With respect to the above three levels of integration the case of Amsterdam is interesting. The High-Speed Line Zuid connecting Amsterdam and Belgium currently stops at Schiphol airport. From there the HSR services continue on the conventional line to the city centre and Amsterdam Centraal station. However, future plans are to make Amsterdam Zuid (station 3 in Figure 2) the HSR station in Amsterdam. The location of this station in the city outskirts is linked to a planning decision to transform the Amsterdam Zuid station into a new CBD for Amsterdam, which in turn was motivated by its good accessibility to the airport (1 station and a few minutes away) and the availability of land for development. Locating the HSR station in Zuid station would further reinforce the new CBD, and in addition it builds on good integration with the local public transport network (several tram, metro and bus lines) and the conventional rail network. It also links in well to the west and south of the country, including HSR services to Germany, and the airport. At Zuid station, there is the 'space' to construct a HSR station and it also means that the expensive construction of the HSR line to the city centre can be avoided. 
Figure 3: Birmingham HSR station catchment area.
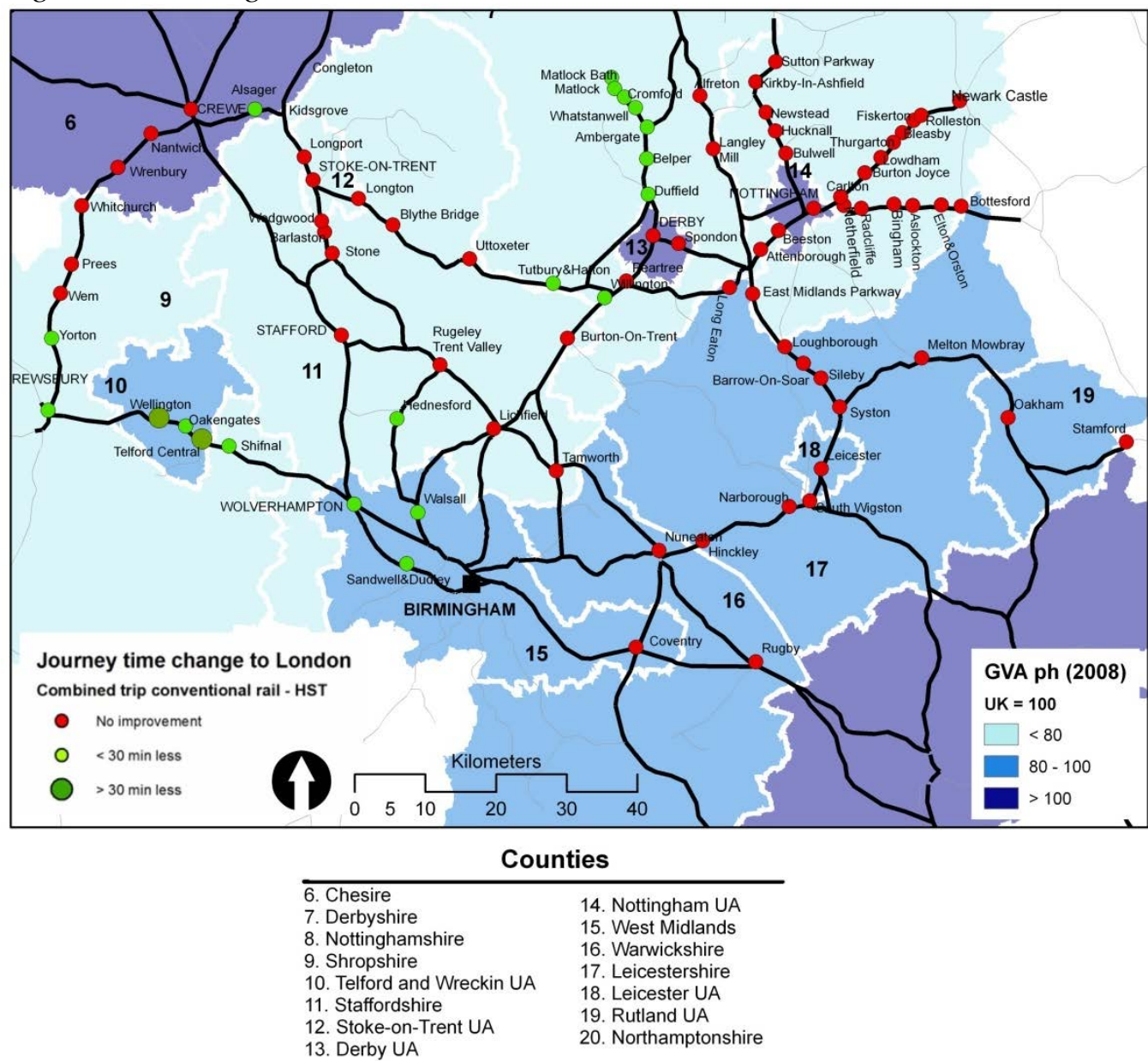

Source: Martínez Sánchez-Mateos and Givoni, 2012.

So the issue of accessibility is central to the arguments for investment in HSR, yet there are many unresolved issues on location, access and integration of the new lines with the existing network. This in turn makes it difficult to identify the wider network effects and the potential for the generation of additional (rather than transferred) economic activity. In the UK, the arguments for HS2 from London to Birmingham has been linked with the debates on the expansion of Heathrow airport ( $3^{\text {rd }}$ Runway), national infrastructure policy and regional development, yet there has been no real discussion over the issue of surface access to Heathrow airport and the role that HSR might play in the providing a key element in a national rail-air strategy.

\section{Conclusions - Principles for "Good" HSR Planning}

The increased interest in rail transport following the introduction of the modern HSR has now spread across the world ${ }^{3}$, and its impact is important and should be welcomed in the context of promoting more sustainable transport and in moving towards low carbon

\footnotetext{
${ }^{3}$ According to the latest data from the International Union of Railways (UIC, 2011), in 2011 there were 17,166 km of high-speed lines (HSLs) worldwide. Additional 8,838 km were under construction (of which $70 \%$ in Asia and 24\% in Europe) and 16,318 km of lines planned (53\% in Europe and 35\% in Asia) across all continents.
} 
mobility. However, the current way in which HSR is framed, envisaged, constructed, and planned does not contribute as much as it should or could. With its emphasis on speed and image, and on the desire to increase the maximum operating speed of future HSR lines, this only reflects part of the potential for HSR. Provided that travel time savings continue to dominate the appraisal of HSR projects, there is a risk that HSR will only contribute to increased mobility. This approach will contribute more rather than less GHG emissions and it will increase in other adverse environmental effect from transport, as well as having social impacts that might restrict access to the HSR services as these "super high speed services” will be directed only at high income and business travellers. This might turn rail transport into a relatively unique and exclusive mode of transport provided in only particular parts (corridors) of a country and serving a particular (and relatively small) part of society. HSR might continue the renaissance of the railways, if measured in passenger$\mathrm{km}$ but it will be a far cry from the (Victorian) high-days of rail transport where, at least in Britain, rail has reached and served almost every part of the country, and most of the population.

Rail has an important role to play in meeting future mobility needs, and a key role in providing long-distance, inter-city surface transport replacing road and air transport and contributing to low carbon mobility. This certainly holds for Europe, but also to other parts of the world. To secure its potential, HSR must be planned differently. It must be planned as the strategic backbone of the transport system, an intermediate mode of transport and a network between urban public transport and long-haul air transport. With this view in mind, and stemming from the above analysis we suggest below seven guiding principles for securing the potential of HSR.

1. Where most travel distances are modest (under $500 \mathrm{~km}$ - this distance allows a return journey to be undertaken in one day), the demands for speed must be placed within a wider framework of reasonable travel times that balance up the frequency of service against the numbers of stops on the route. The proposal here is that average speeds should be about $200 \mathrm{~km} / \mathrm{hr}$;

2. More consideration needs to be given to the numbers of stations on the route, as speed and frequency is also determined by the numbers of stations. These stations should be strategically located so that there are high quality and frequent linkages to the local public transport network. There seems to be tendency to place the HSR stations on the periphery in smaller cities rather than in the centre;

3. More generally integration with the rest of the transport network must be a key priority for HSR. This strategic objective relates to local accessibility (point 2), but also to regional accessibility where larger potential catchment areas exist, and to international linkages through airport and HSR connectivity. The attractiveness of using HST in respect of other modes depends on the ease of getting to the station and the speed of doing so. The number of stations must be minimised but their accessibility maximised. This is achieved through integration of HSR with the rest of the transport system and key decisions on station location and the numbers of stations;

4. There is considerable potential for development around HSR stations, and for the stations themselves to become centres of economic activity, due to their accessibility and potential for income generation. There is a debate not fully resolved that has been covered here on the relative merits of different station location alternatives. This suggests that different options can be considered 
according to different city development priorities, and this relates to points 1-3 above;

5. There should be a much greater flexibility in the types of service being offered on HSR as the market is not homogeneous, but heterogeneous, and quality of service is central to long term viability. This includes the possibility of different types of service for different users, but in all cases the HSR part of a journey should be seen as part of the total door to door experience of travel. The provision of a wide range of services and facilities for use 'en route' is part of the modern view of travelling where quality time can be spent in travel. HSR has to appeal to all sections of the population, and this means affordability is a key determinant;

6. Finance is likely to become even more difficult to put together as new HSR schemes become increasingly expensive. It has been seen that in the EU27, there has already been a switching of funding away from the European sources to national and local sources. Increasingly, new forms of finance are required that combine the HSR investment with wider economic development objectives, so that the transport investment is seen as part of a wider strategy. As noted above, the HSR investment is really part of an integrated transport system that combines the best of all modes, but there is also considerable potential to link it in with wider regeneration and development objectives;

7. In the EU27, the current generation of HSR have been in service for nearly 40 years, and this means that new rolling stock and other investments need to be revisited (e.g. signalling and stations). This reinvestment in existing lines is in addition to any desire to build new lines. It does provide the opportunity to look at making the trains more attractive to a wider range of potential users and uses. The image of modernity and speed have been established as the trade mark of the HST, but that image needs to be supplemented by the quality of the on board services being provided, the reliability and comfort of the train, the ease of transition from one mode to another, and other means to reinforce the positive.

Perhaps in Europe it is time to review the progress that has been made in reinventing rail travel over the last 16 years, and the key role that HSR has played in that process. By thinking strategically and by embedding all rail services (including HSR) in the national and international transport network, it is possible to move away from the view that all modes compete with each other (the traditional view) towards an integrated set of transport or mobility services that meet the needs of all travellers by providing high quality door-todoor travel. Such an innovative view, where the different modes work in combination together to provide mobility services would mean that the long term future of HSR and all rail services is assured, as well as its contribution to sustainability.

\section{References}

Banister, D. (2008) The sustainable mobility paradigm. Transport Policy, 15: 73-80.

Banister, D (2011) The trilogy of distance, speed and time, Journal of Transport Geography 19(4): 950-959.

Brons, M., Givoni, M. and Rietveld, P. (2009) Access to railway stations and its potential in increasing rail use. Transportation Research Part A, 43: 136-149. 
Chester, M. V., Horvath, A. (2010) Life-cycle Assessment of High-speed Rail: the Case of California. Environmental Research Letters, 5(1): 014003.

Chou J.-S., Kim C., Kuo Y.-C., Ou N.-C. (2011) Deploying effective service strategy in the operations stage of high-speed rail. Transportation Research Part E: Logistics and Transportation Review, 47 (4): 507-519.

Crozet, Y (2011) HSR and Interurban Mobility: Who Are the Winners?, Paper presented at the Conference on Realising the Vision of a High Speed Rail System in California, Berkeley, May.

Debrezion, G. (2006) Railway impacts on real estate prices, PhD Thesis, Amsterdam: Vrije Universiteit.

DG TREN (2013) EU transport in Figures: Statistical Pocketbook 2013, Brussels, European Union, http://ec.europa.eu/transport/facts-fundings/statistics/pocketbook-2013_en.htm Accessed 27th July 2013

EC (2005) Trans European Transport Network - TEN-T Priority Axes and Projects 2005, Brussels.

EC (2011) Roadmap to a Single European Transport Area - Towards a competitive and resource efficient transport system, COM(2011) 144 Final, Brussels.

EC (2012) Connecting Europe Facility: Investing in Europe’s Growth 2014-2020, Brussels, European Union, October.

Givoni, M. and Banister, D. (2006) Airline and railway integration. Transport Policy, 13: 386-397.

Givoni, M. and Banister, D. (2007) The role of the railways in the future of air transport. Transport Planning and Technology, 30(1): 95-112.

Givoni, M. and Banister, D. (2012a) Reinventing the wheel: Planning the rail network to meet the mobility needs of the $21^{\text {st }}$ century, in Frenkel, A. Nijkamp, P. and McCann, P. (eds) Societies and Motion: Innovation, Migration and Regional Transformations, Cheltenham: Edward Elgar, pp320342.

Givoni, M and Banister, D (2012b) Speed: The less important element of the High Speed Train, Journal of Transport Geography 22: 306-307.

Givoni, M., Brand, C., Watkiss, P. (2009) Are railways 'climate friendly'?, Built Environment, 35(1): 70-86.

Givoni, M. and Rietveld, P. (2008) Rail Infrastructure at major European Hub Airports - the Role of Institutional Settings. In, H. Priemus, B. van Wee and B. Flyvbjerg (eds.) Decision-Making on Mega-Projects: Cost-benefit Analysis, Planning and Innovation, Edward Elgar, 281-303.

Givoni, M., and Rietveld, P. (2011) Access to rail in urban areas: examination of the number of stations. In Button, K. and A., Reggiani (eds.) Transportation and Economic Development Challenges, Edward-Elgar, 85-99.

Givoni, M. and Rietveld, P (2013) Do cities deserve more railway stations? The choice of a departure railway station in a multiple-station region, Paper submitted to the Journal of Transport Geography.

Graham, D and Melo, P (2010) Advice on the assessment of the wider economic impacts: A report for HS2, Imperial College, March, http://webarchive.nationalarchives.gov.uk/+/http:/www.dft.gov.uk/pgr/rail/pi/highspeedrail/hs2ltd/a ppraisalmaterial/pdf/widereconomicreport.pdf - last accessed 6th November 2012.

Martínez Sánchez-Mateos, HS and Givoni, M (2012) The accessibility impact of a new High-Speed Rail line in the UK - a preliminary analysis of winners and losers, Journal of Transport Geography 25: $105-114$. 
UIC (2011) High Speed Lines in the World. Available at

http://www.uic.org/IMG/pdf/20111101_a1_high_speed_lines_in_the_world.pdf.

Ureña, J.M, Menerault, P., and Garmendia, M. (2009) The high-speed rail challenge for big intermediate cities: A national, regional and local perspective. Cities, 26: 266279.

Vickerman, R (2007) Recent evolution of research into the wider economic benefits of infrastructure investment, Discussion Paper 2007-9, Prepared for the Joint Transport Research Centre OECD and the International Transport Forum, December.

Words 7400

\begin{abstract}
:
High speed rail (HSR) can potentially transform the geography of a country, bringing regions and cities closer to each other by improving accessibility. Such benefits in turn can be the basis for creating (regional) economic development, and this is often a major factor in promoting the higher costs of HSR investment. The key factors here concern the role and position of the HSR in the local, regional and national transport systems, and this may be more important than the speed of the service. Two factors are central to the planning of HSR lines. The first relates to the numbers and locations of stations on the HSR network, and the second to how these stations are integrated into the rest of the transport network. This paper reviews current financing and trends in European rail travel, concentrating on the recent developments in HSR. It then addresses these two issues of station location and integration across connecting transport services. Rail has an increasingly important role to play in providing mobility between the major cities in Europe, and it is likely to provide much of the necessary capacity for the expected growth in long distance travel. A dedicated HSR network might be a good option to achieve this role, but such a network needs to be planned as the strategic backbone of the transport system.
\end{abstract}

